\title{
Comparison of fermentation properties in raw and boiled legumes after simulated digestion
}

U. Wimalaweera, A. Deen, R Visvanathan, S.M. Sewwandi, S. Wickramanayake, D. Wickramarachchi, N. Marikkar, I. Ratnayake, B.C. Jayawardana and R. Liyanage*
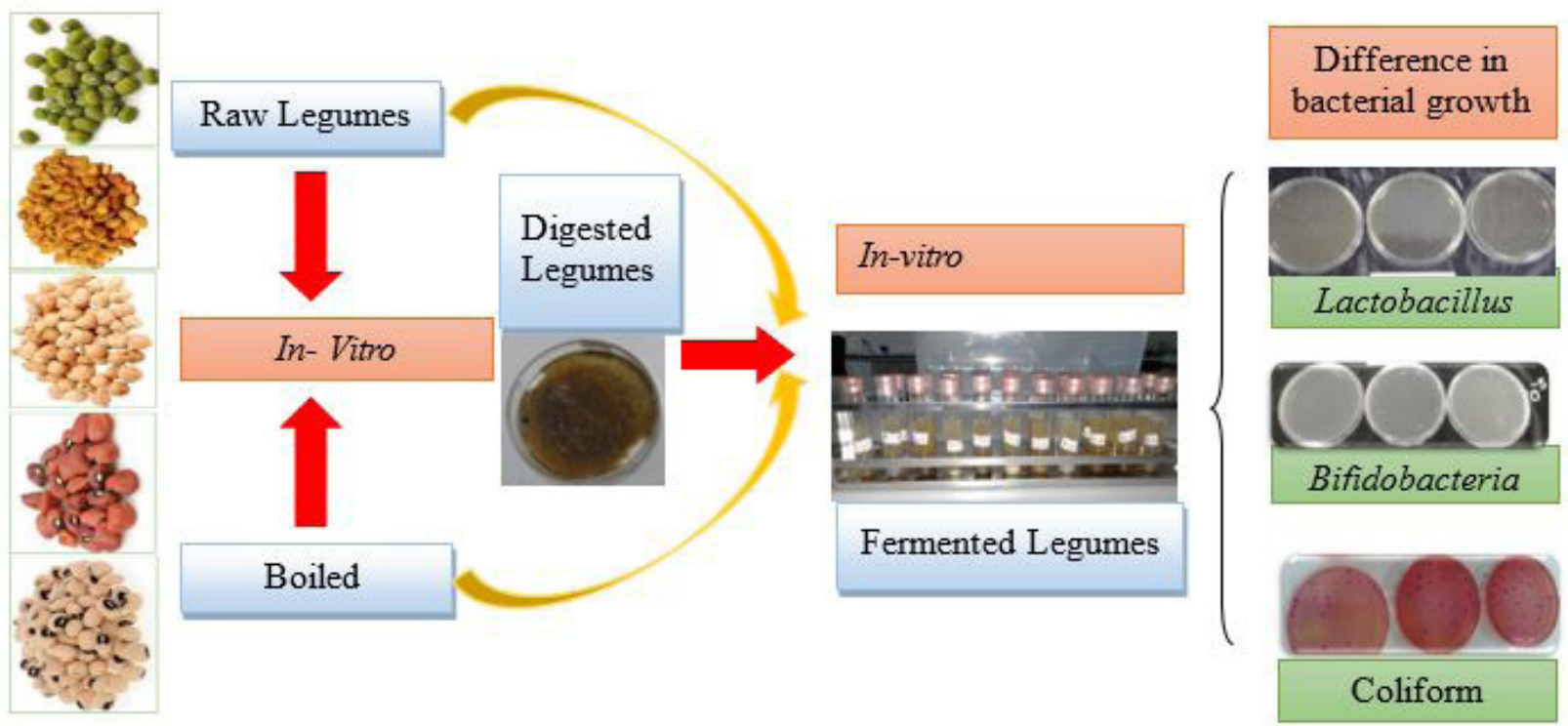

\section{Highlights}

- Chickpea showed the highest prebiotic potential.

- Simulated digestion differently modulated prebiotic potential of legumes.

- Boiled legumes showed better prebiotic potential than their raw powders. 


\title{
RESEARCH ARTICLE
}

\section{Comparison of fermentation properties in raw and boiled legumes after simulated digestion}

\author{
U. Wimalaweera ${ }^{1}$, A. Deen ${ }^{2,3}$, R. Visvanathan ${ }^{2}$, S.M.Sewwandi ${ }^{2,3}$, S. Wickramanayake ${ }^{1}$, D. Wickramarachchi ${ }^{2}$, \\ N. Marikkar ${ }^{4}$, I. Ratnayake ${ }^{2}$, B.C. Jayawardana ${ }^{1}$ and R. Liyanage, ${ }^{2, *}$
}

${ }^{1}$ Department of Animal Science, Faculty of Agriculture, University of Peradeniya, Peradeniya, Sri Lanka. ${ }^{2}$ Laborotary of Nutritional Biochemistry, National Institute of Fundamental Studies, Hanthana Road, Kandy, Sri Lanka. ${ }^{3}$ Postgraduate Institute of Science, University of Peradeniya, Peradeniya, Sri Lanka.

${ }^{4}$ Laboratory of Food Chemistry, National Institute of Fundamental Studies, Hanthana Road, Kandy, Sri Lanka.

Received: 12/06/2020; Accepted: 02/10/2020

\begin{abstract}
This study compared the fermentation properties of selected raw and boiled legumes after simulated digestion. Raw and boiled; mung bean, two cowpea cultivars (Waruni and Dhawala), horse gram, and chickpea were subjected to simulated digestion and fermentation using swine gastric and intestinal juices and cecal bacteria. Simulated digestion significantly ( $p$ $<0.05$ ) reduced prebiotic potential of some legume substrates except boiled; mung bean, Waruni, chickpea, Dhawala, and raw; Dhawala and horse gram. Digested residues of boiled chickpea, horse gram, and Waruni showed significantly $(\mathrm{p}<0.05)$ higher Bifidobacterium proliferation ability when compared to digested residues of boiled mung bean and Dhawala. Even after simulated digestion, chickpea showed the highest $(\mathrm{p}<0.05)$ prebiotic potential compared to other legumes. Findings displayed that simulated digestion differently modulated the fermentation properties of both raw and boiled legumes. In conclusion, boiled legumes are more suitable than their raw powders for preparing prebiotic foods.
\end{abstract}

Keywords: Legumes; digestion; fermentation; boiled; raw; prebiotic.

\section{INTRODUCTION}

The gastrointestinal microbiota plays a vital role in modulating metabolic, immunologic, and protective functions of the human body (Holscher, 2017). Consumption of a variety of dietary fibers and resistant starches is an excellent dietary strategy for modulating compositional variability as well as the metabolic activity of the intestinal microorganisms (Holscher, 2017). Prebiotics found in natural food sources are non-digestible carbohydrates such as resistant starch (RS), galactooligosaccharides (GOS), fructooligosaccharides (FOS), xylooligosaccharides (XOS), pectic oligosaccharides (POS), and various oligosaccharides which may act as fermentable carbohydrates for beneficial colon microorganisms (Gómez et al., 2016; Scott et al., 2013). The metabolic end products synthesized in the lower part of the gastrointestinal tract during fermentation and the bacterial populations present might vary according to the nature and the amount of non-digestible carbohydrate ingested (Rowland et al., 2018; Rawi et al., 2020). Generally, fermentation of non-digestible carbohydrates, proteins, and other fibers in the large intestine produces beneficial as well as nonbeneficial compounds that could affect the bowel health. Short-chain fatty acids (SCFA) such as acetic, propionic, and butyric are some of them which may confer various health benefits to human beings (Aquino et al., 2017; Rowland et al., 2018). Probiotic bacterial species, mainly Bifidobacterium and Lactobacillus, are responsible for the production of these short-chain fatty acids, mostly due to the fermentation of dietary oligosaccharides (Fernando et al., 2010). Furthermore, the fermentation process by beneficial microorganisms is vital in reducing the population of pathogenic microorganisms in the gut due to the significant reduction of colonic $\mathrm{pH}$ (Aquino et al., 2017; Campbell et al., 1997).

Legumes are good sources of prebiotic carbohydrates for improving gastrointestinal health (Chen et al., 2020; Rengadu et al., 2020). Among the Asian countries, legumes such as chickpea and mung bean are widely consumed while cowpea and horse gram are utilized minimally. These legumes are consumed mainly after boiling, and some are used in raw powder form in food product preparations. It is well known that the processing and gastrointestinal digestion modulate fermentation properties of food (Capuano, 2016; Singh, 1988). To our knowledge, comparative information on the prebiotic activity of raw and boiled legumes after in vitro enzymatic digestion is scanty, and this information is vital in developing functional food with desired nutritional properties. Hence, the objective of this study is to investigate the fermentation properties of five types of raw and boiled commonly consumed legumes in Sri Lanka (mungbean, two cowpea cultivars (Waruni, Dhawala), chickpea and horse gram) after in-vitro enzymatic digestion. 


\section{MATERIALS AND METHODS}

\section{Materials}

Mung bean (MI5) (Vigna radiata L), cowpea (Dhawala $\&$ Waruni) (Vigna unguiculata L) grown in Sri Lanka were purchased from the Government Seed Centre, Dambulla, Sri Lanka. Horse gram (Macrotyloma uniflorum) was purchased from Grain Legumes and Oil Seed Crops Research and Development Centre, Agunakolapelessa (GLOSCRD), Sri Lanka.

Chickpea (Cicer arietinum L), which is not grown in Sri Lanka, was purchased from Kandy Market, Sri Lanka. Seeds were manually selected to remove impurities before the experiment. The selected legume seeds were stored at $-4^{\circ} \mathrm{C}$ until use. Bifidobacterium AGAR (HiMedia Laboratories PVT, Ltd., India), M.R.S. AGAR (OXOID LTD, England), and MacConkey AGAR (OXOID LTD, England) were used for culturing of Bifidobacterium, Lactobacillus, and Coliform bacterial species, respectively. Peptone water solution (M028-100G HIMEDIA peptone water, HiMedia Laboratories Pvt, Ltd., India) was used to prepare serial dilutions from fermented solution. All other chemicals used were of analytical grade and purchased from SigmaAldrich (Sigma, St. Louis, U.S.A.) unless otherwise stated.

\section{Sample preparation}

Legume seeds were soaked overnight in water before boiling. Seeds were boiled until they were sufficiently softened to be kneaded with one's hands. The amount of water added and the duration required for boiling (Table 1) were decided as previously described (Mtolo et al., 2017; Prinyawiwatkul et al., 1997). Boiled and raw seeds were ground using a grinder. Then the samples were pre-dried to a constant weight at $60{ }^{\circ} \mathrm{C}$ using a drying oven (Mermmert ${ }^{\mathrm{TM}}$ VO200, Germany) and packed in polythene bags separately and stored in a desiccator for further analysis.

\section{In-vitro digestion of legume samples Collection of gastric and intestinal juices}

Gastric juice and intestinal juice were collected from the slaughterhouse of Mawelawattha livestock field station, Faculty of Agriculture, University of Peradeniya, Sri Lanka. Stomach and intestinal content of slaughtered pigs were squeezed out to collect gastric and intestinal juice and filtered through a clean muslin cloth. A cool box was used to store collected samples during the transportation. Juices were stored at $-20{ }^{\circ} \mathrm{C}$ until the process.

\section{Preparation of gastric enzyme solution}

Collected gastric juice was centrifuged (LEGENDXIR Centrifuge, Germany) at $1250 \mathrm{rpm}$ for $10 \mathrm{~min}$ at $5{ }^{\circ} \mathrm{C}$ (Furuya et al., 1979). Then, the supernatant was collected and stored at $-20^{\circ} \mathrm{C}$ in a refrigerator until use.

\section{Preparation of intestinal enzyme solution}

Collected intestinal juice was centrifuged using a centrifuge (LEGEND XIR Centrifuge, Germany) at $4500 \mathrm{rpm}$ for 10 min at $5{ }^{\circ} \mathrm{C}$ (Furuya et al., 1979). Then the supernatant was collected and stored at $-20^{\circ} \mathrm{C}$ in a refrigerator until use.

\section{Digestion of legumes}

According to the methods described by Furuya et al. (1979) and Li et al. (2004), legume samples were digested with minor modifications. Ground legume sample (2 g) was measured (RADWAG Wagi Elekroniczne, Poland) into $100 \mathrm{~mL}$ conical flask, to which $20.0 \mathrm{~mL}$ of gastric juice was added, and its $\mathrm{pH}$ was adjusted in a range of 4.0-4.6 using a $\mathrm{pH}$ meter (HANNA Instrument Inc, Woonsocket). This mixture was incubated in a shaking incubator at $100 \mathrm{rpm}$ (THZ-100 Shaking Incubator, Biocotek, China) for $4 \mathrm{~h}$ at $37^{\circ} \mathrm{C}$. At the end of the first incubation period, the contents were neutralized with $1.0 \mathrm{~mol} \mathrm{dm}^{-3}$ sodium hydroxide solution. In the second stage, $20.0 \mathrm{~mL}$ of intestinal fluid prepared as mentioned previously was added, the $\mathrm{pH}$ was adjusted (6.9-7.4) and the digestion mixtures were incubated further in a shaking incubator for additional 4 $\mathrm{h}$ at $37^{\circ} \mathrm{C}$ at $100 \mathrm{rpm}$. After the second incubation, the contents of the flask were transferred to centrifuge tubes and centrifuged (LEGEND XIR Centrifuge, Germany) immediately at $4500 \mathrm{rpm}$ for $10 \mathrm{~min}$ at $5{ }^{\circ} \mathrm{C}$. The supernatant fraction was discarded, and the precipitate was mixed with a little water and filtered through a filter paper (Toyo-Roshi No. 5A, Toyo-Roshi, Tokyo, Japan) and oven-

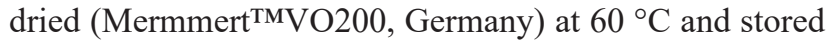
at $-20{ }^{\circ} \mathrm{C}$ in a refrigerator until use.

\section{In-vitro fermentation of legume samples Preparation of bacterial pellets}

Ceca were collected from two healthy swine of slaughter unit of Mawelawattha Livestock field station, Department of Animal Science, Faculty of Agriculture, University of Peradeniya, Sri Lanka. Two healthy swine which had not received any antibiotic treatment within the last three months were selected and slaughtered after $16 \mathrm{~h}$ fast, and ceca were quickly removed and taken into the National

Table 1: Requirements for boiling of different legume seeds.

\begin{tabular}{ccc}
\hline Legume seed & W/V ratio & Time period (minutes) \\
\hline Mungbean & $1: 3$ & 30 \\
Waruni & $1: 6$ & 30 \\
Dhawala & $1: 6$ & 30 \\
Horsegram & $1: 7$ & 47 \\
Chickpea & $1: 5$ & 40 \\
\hline
\end{tabular}


Institute of Fundamental Studies by maintaining anaerobic conditions. Twenty five grams of cecal content was measured by an electronic weighing balance (RADWAG Wagi Elekroniczne, Poland) and dissolved in $250.0 \mathrm{~mL}$ of phosphate buffer $(\mathrm{pH} 6.2 \pm 0.2 \mathrm{pH}$ ). Then the cecal solution was filtered twice using a pre-sterilized muslin cloth. Bacterial pellets were obtained by centrifuging using (LEGEND XIR Centrifuge, Germany) the filtrate at 5 ${ }^{\circ} \mathrm{C}$ for $15 \mathrm{~min}$ at a speed of $10000 \mathrm{rpm}$. Bacterial pellets were resuspended in $250.0 \mathrm{~mL}$ of phosphate buffer $(\mathrm{pH}$ $6.2 \pm 0.2 \mathrm{pH})$.

\section{Fermentation of legume samples}

Digested legumes $(0.5 \mathrm{~g})$ were accurately measured using an electronic weighing balance (RADWAG Wagi Elekroniczne, Poland) and added to the vacutainer tubes. $8.0 \mathrm{~mL}$ from bacterial pellet solution was added into those vacutainers and exposed to a continuous $\mathrm{CO}_{2}$ flow as described by Calabrò et al., (2009). Bacterial suspension $(8.0 \mathrm{~mL})$ without the substrate was used as a control. Vacutainers were appropriately sealed and incubated using Mermmert incubator (Mermmert ${ }^{\mathrm{TM}}$ IN160, Germany) at 37 ${ }^{\circ} \mathrm{C}$ for $4 \mathrm{~h}$.

\section{Microbial growth analysis}

Total anaerobe bacterial counts for each legume fermented with bacterial pellets were taken as previously described by the spread plate method (Garcha et al., 2016). Fermented legume samples were serially diluted with peptone water and inoculated on plates prepared from Bifidobacterium AGAR, M.R.S. agar, and MacConkey agar. All the plates were placed in the Mermmert incubator (Mermmert ${ }^{\mathrm{TM}}$ IN160, Germany) under anaerobic conditions at $37{ }^{\circ} \mathrm{C}$. Plates having bacterial colonies within a range of 25-250 were selected for calculations.

$$
\frac{\mathrm{CFU}}{\mathrm{mL}}=\left(\begin{array}{c}
\text { Number } \\
\text { of Colonies }
\end{array}\right) \times \frac{1}{\left(\begin{array}{c}
\text { Dilution } \\
\text { factor }
\end{array}\right)} \times \frac{1}{\left(\begin{array}{c}
\text { innoculated } \\
\text { volume }
\end{array}\right)}
$$

\section{Statistical analysis}

The tests were performed in triplicate for each sample to be analyzed. All the data were expressed as mean \pm standard deviation. Data were analyzed using the S.A.S. software package (S.A.S. institution Inc., 2003, Cary, U.S.A.). Three-Way ANOVA was used for the analysis. Means separations were analyzed along the column and raw using Duncan's Multiple Range Test and Dennet's Test at $\alpha=$ 0.05. Following statistical model was used:

$$
\begin{aligned}
\text { Yijkl }=\mu+\alpha i+\varepsilon j+\gamma \mathrm{k} & +\alpha \varepsilon \mathrm{ij}+ \\
& \alpha \gamma \mathrm{ik}+\varepsilon \gamma \mathrm{jk}+\alpha \varepsilon \gamma \mathrm{ijk}
\end{aligned}
$$

\section{RESULTS AND DISCUSSION}

Any dietary material that is not digestible by mammalian gastric enzymes and enters the large intestine and degraded by intestinal microflora are considered as prebiotics (Gibson et al., 2010; Nakata et al., 2017). In this study, before doing in vitro fermentation, legumes samples were subjected to simulated gastrointestinal digestion to investigate legumes> actual effectiveness as prebiotic candidates. The findings of this study have shown that in vitro digestion modulated the prebiotic potential of both raw and boiled legumes. Simulated digestion significantly reduced $(\mathrm{p}<0.05)$ prebiotic potential in some legume substrates except boiled, mung bean, Waruni cowpea (red cowpea), chickpea, Dhawala cowpea and raw; Dhawala cowpea and horse gram showing that true prebiotic potential can vary among legumes. Structural and compositional differences in dietary substrates could be the reason behind the differential growth pattern of microorganisms (Holscher, 2017). Observed differences in fermentation properties among different legumes in this study could be due to the differences in physicochemical properties of prebiotic carbohydrates, including sugar composition, branching, chain length, degree of polymerization, and solubility (Holscher, 2017; Siva et al., 2019).

Digested residues of boiled chickpea and digested residues of boiled Waruni samples showed significantly higher $(\mathrm{p}<0.05)$ Bifidobacterium fermentation ability than digested residues of boiled mung bean and Dhawala (Table 2).

Further, digested residues of boiled and undigested raw chickpea showed significantly higher $(\mathrm{p}<0.05)$ Lactobacillus fermentation properties (Table 3 ) compared to other digested residues of boiled legumes and undigested raw legumes. Significantly higher $(p<0.05)$ prebiotic potential shown by digested boiled chickpeas samples in this study may be due to the availability of a higher concentration of readily fermentable components in chickpea, which escape pepsin and pancreatin digestion (Woyengo et al., 2017). It has been shown that chickpea contains a significantly higher amount of polyols, a group of low digestible carbohydrates compared to peas, beans, and lentils (Moussou et al.,2017), which may be another reason for rapid fermentation shown by chickpea compared to some other legumes.

Prebiotics should be able to selectively metabolize Lactobacillus and Bifidobacterium at a higher degree compared to pathogenic bacteria. Significantly higher $(\mathrm{p}<0.05)$ prebiotic potential in chickpea was further supported by a significantly lower $(p<0.05)$ Coliform population observed for digested boiled residues of chickpea (Table 3) compared to other legume substrates (Akillioglu \& Karakaya, 2010). Abundantly available $\alpha$-galactosides and oligosaccharide; ciceritol in chickpea may have stimulated the growth of probiotic bacteria and inhibited the pathogenic bacteria, as shown previously (Dai et al., 2017; Muzquiz et al., 2012). Digested residues of raw horse gram showed a significantly higher $(\mathrm{p}<0.05)$ Bifidobacterium fermentation ability compared to digested residues of raw mungbean, Waruni, and Dhawala (Table 2).

These observations may be supported higher content of oligosaccharides in cotyledon fractions of horse gram seeds (Prasad \& Singh, 2014). Significantly higher $(p<0.05)$ Bifidobacterium proliferation ability observed for digested residues of boiled Waruni and significantly higher $(p<0.05)$ Coliform suppression ability (Table 4$)$ shown by 
Table 2: The effect of In-vitro digestion and fermentation on Cecal Bifidobacterium growth ( $\log \mathrm{CFU} / \mathrm{mL})$.

\begin{tabular}{lcccc}
\cline { 1 - 4 } Substrate & \multicolumn{2}{c}{ Undigested } & \multicolumn{2}{c}{ Digested } \\
& \multicolumn{1}{c}{ Raw } & Boiled & Raw & boiled \\
\hline Chickpea & $8.55^{\mathrm{a}, \mathrm{A}} \pm 0.01$ & $8.43^{\mathrm{a}, \mathrm{B}} \pm 0.01$ & $8.15^{\mathrm{ab}, \mathrm{C}} \pm 0.04$ & $8.04^{\mathrm{a}, \mathrm{D}} \pm 0.05$ \\
Horse gram & $8.30^{\mathrm{b}, \mathrm{A}} \pm 0.01$ & $8.09^{\mathrm{b}, \mathrm{B}} \pm 0.03$ & $8.30^{\mathrm{a}, \mathrm{A}} \pm 0.02$ & $7.90^{\mathrm{ab}, \mathrm{C}} \pm 0.04$ \\
Mung bean & $7.73^{\mathrm{c}, \mathrm{A}} \pm 0.09$ & $7.89^{\mathrm{c}, \mathrm{A}} \pm 0.04$ & $7.56^{\mathrm{c}, \mathrm{B}} \pm 0.15$ & $7.78^{\mathrm{b}, \mathrm{A}} \pm 0.03$ \\
Waruni & $8.30^{\mathrm{b}, \mathrm{A}} \pm 0.02$ & $8.04^{\mathrm{b}, \mathrm{B}} \pm 0.02$ & $7.53^{\mathrm{c}, \mathrm{C}} \pm 0.02$ & $7.98^{\mathrm{a}, \mathrm{B}} \pm 0.06$ \\
Dhawala & $7.83^{\mathrm{c}, \mathrm{B}} \pm 0.02$ & $7.83^{\mathrm{c}, \mathrm{B}} \pm 0.04$ & $8.01^{\mathrm{b}, \mathrm{A}} \pm 0.05$ & $7.18^{\mathrm{c}, \mathrm{C}} \pm 0.09$ \\
Control & $6.40^{\mathrm{d}} \pm 0.17$ & $6.40^{\mathrm{d}} \pm 0.17$ & $6.40^{\mathrm{d}} \pm 0.17$ & $6.40^{\mathrm{d}} \pm 0.17$ \\
& & & & \\
\hline
\end{tabular}

Values are expressed as means $\pm \mathrm{SD}$.

Mean values within a column with lowercase superscript letters are significantly different at $(\mathrm{P}<0.05)$.

Mean values within a raw with different uppercase superscript letters are significantly different at $(\mathrm{P}<0.05)$.

Table 3: The effect of in-vitro digestion and fermentation on Cecal Lactobacillus growth ( $\log \mathrm{CFU} / \mathrm{mL})$.

\begin{tabular}{lcccc}
\hline \multicolumn{1}{c}{ Substrate } & \multicolumn{2}{c}{ Undigested } & \multicolumn{2}{c}{ Digested } \\
& Raw & Boiled & Raw & Boiled \\
\hline Chickpea & $8.80^{\mathrm{a}, \mathrm{A}} \pm 0.58$ & $7.89^{\mathrm{a}, \mathrm{B}} \pm 0.60$ & $6.82^{\mathrm{d}, \mathrm{C}} \pm 0.03$ & $8.32^{\mathrm{a}, \mathrm{AB}} \pm 0.01$ \\
Horse gram & $7.71^{\mathrm{b}, \mathrm{B}} \pm 0.02$ & $8.27^{\mathrm{a}, \mathrm{A}} \pm 0.54$ & $7.22^{\mathrm{b}, \mathrm{B}} \pm 0.04$ & $7.32^{\mathrm{d}, \mathrm{B}} \pm 0.01$ \\
Mung bean & $7.61^{\mathrm{b}, \mathrm{C}} \pm 0.03$ & $7.83^{\mathrm{a}, \mathrm{A}} \pm 0.02$ & $7.26^{\mathrm{b}, \mathrm{D}} \pm 0.04$ & $7.71^{\mathrm{b}, \mathrm{B}} \pm 0.00$ \\
Waruni & $7.60^{\mathrm{b}, \mathrm{B}} \pm 0.01$ & $7.83^{\mathrm{a}, \mathrm{A}} \pm 0.02$ & $7.35^{\mathrm{a}, \mathrm{C}} \pm 0.04$ & $7.40^{\mathrm{c}, \mathrm{C}} \pm 0.01$ \\
Dhawala & $7.67^{\mathrm{b}, \mathrm{A}} \pm 0.01$ & $7.65^{\mathrm{a}, \mathrm{A}} \pm 0.01$ & $7.25^{\mathrm{b}, \mathrm{A}} \pm 0.01$ & $7.70^{\mathrm{b}, \mathrm{A}} \pm 0.01$ \\
Control & $7.00^{\mathrm{c}} \pm 0.03$ & $7.00^{\mathrm{b}} \pm 0.03$ & $7.00^{\mathrm{c}} \pm 0.03$ & $7.00^{\mathrm{e}} \pm 0.03$ \\
\hline
\end{tabular}

Values are expressed as means $\pm \mathrm{SD}$.

Mean values within a column with lowercase superscript letters are significantly different at $(\mathrm{P}<0.05)$.

Mean values within a raw with different uppercase superscript letters are significantly different at $(\mathrm{P}<0.05)$.

Table 4 :The effect of in vitro digestion and fermentation on Cecal Coliform growth ( $\log \mathrm{CFU} / \mathrm{mL})$.

\begin{tabular}{lrrrr}
\hline \multirow{2}{*}{ Substrate } & \multicolumn{2}{c}{ Undigested } & \multicolumn{2}{c}{ Digested } \\
\cline { 2 - 5 } & \multicolumn{1}{c}{ Raw } & \multicolumn{1}{c}{ Boiled } & \multicolumn{1}{c}{ Raw } & \multicolumn{1}{c}{ Boiled } \\
\hline Chickpea & $6.94^{\mathrm{d}, \mathrm{B}} \pm 0.04$ & $6.87^{\mathrm{c}, \mathrm{C}} \pm 0.02$ & $7.36^{\mathrm{b}, \mathrm{A}} \pm 0.02$ & $6.70^{\mathrm{c}, \mathrm{B}} \pm 0.05$ \\
Horse gram & $7.89^{\mathrm{a}, \mathrm{A}} \pm 0.01$ & $7.70^{\mathrm{a}, \mathrm{C}} \pm 0.04$ & $7.78^{\mathrm{a}, \mathrm{B}} \pm 0.01$ & $7.18^{\mathrm{b}, \mathrm{D}} \pm 0.03$ \\
Mung bean & $7.36^{\mathrm{c}, \mathrm{A}} \pm 0.31$ & $7.68^{\mathrm{b}, \mathrm{A}} \pm 0.17$ & $7.26^{\mathrm{c}, \mathrm{A}} \pm 0.01$ & $7.16^{\mathrm{b}, \mathrm{A}} \pm 0.09$ \\
Waruni & $7.54^{\mathrm{bc}, \mathrm{B}} \pm 0.01$ & $7.68^{\mathrm{a}, \mathrm{A}} \pm 0.04$ & $7.39^{\mathrm{b}, \mathrm{C}} \pm 0.09$ & $7.33^{\mathrm{a}, \mathrm{C}} \pm 0.02$ \\
Dhawala & $7.63^{\mathrm{b}, \mathrm{B}} \pm 0.03$ & $7.70^{\mathrm{a}, \mathrm{A}} \pm 0.01$ & $6.82^{\mathrm{d}, \mathrm{D}} \pm 0.02$ & $6.97^{\mathrm{c}, \mathrm{C}} \pm 0.03$ \\
Control & $6.38^{\mathrm{e}} \pm 0.07$ & $6.38^{\mathrm{d}} \pm 0.07$ & $6.38^{\mathrm{e}} \pm 0.07$ & $6.38^{\mathrm{d}} \pm 0.07$
\end{tabular}

Values are expressed as means \pm SD.

Mean values within a column with lowercase superscript letters are significantly different at $(\mathrm{P}<0.05)$.

Mean values within a raw with different uppercase superscript letters are significantly different at $(\mathrm{P}<0.05)$. 
digested residues of both raw and boiled Dhawala cowpea were supported by previous findings showing that resistant starch isolated from five cowpea cultivars fulfilled the criteria to be classified as prebiotics (Rengadu et al., 2020).

Digested residues of boiled mung bean and Waruni cowpea and digested residues of boiled chickpea and mung bean significantly improved the $(\mathrm{p}<0.05)$ Bifidobacterium and Lactobacilli growth, respectively and digested residues of boiled chickpea, horse gram and Dhawala significantly suppressed $(\mathrm{p}<0.05)$ the Coliform growth compared to their respective raw digested samples suggesting that boiling improved the prebiotic potential of most of the studied legumes. Significantly higher prebiotic potential in digested boiled legumes than digested raw legumes may be due to the increase in soluble fiber composition observed for mung beans upon boiling (Liyanage et al., 2018). It has been shown that soluble residues have a much more positive effect on gut microbiota (Chen et al., 2020). Further, previous studies have shown that processing not only altered the yield of soluble and insoluble fiber fractions, it also changed the fiber composition and sugar profiles of the two fiber fractions (Chang et al., 1989). Moreover, the increase in resistant starch content with the retrogradation of legume flours after boiling may have modulated the growth of probiotic bacteria (Dangsungnoen et al., 2012). However, digested residues of raw Dhawala and raw horse gram showed significantly higher $(\mathrm{p}<0.05)$ Bifidobacterium proliferation than their digested boiled samples showing that some legumes show higher prebiotic potential in raw forms than when they are boiled. Findings further supported the previous study showing that the prebiotic activity of digested substrates was greatly affected by legume type, boiling, and composition of digesta (Chen et al., 2020).

\section{CONCLUSION}

This study displayed that simulated digestion differently modulated the fermentation properties of both raw and boiled legumes. Among all the studied legume samples, boiled chickpea could be considered as the best prebiotic candidate considering both Bifidobacterium and Lactobacillus proliferation ability. Boiled mung bean, boiled chickpea, and boiled Waruni cowpea may be more suitable than their raw forms in preparing prebiotic food.

\section{ACKNOWLEDGEMENT}

The authors are grateful for the assistance given by the Mawelawattha Livestock field station, Department of Animal Science, Faculty of Agriculture, University of Peradeniya, Sri Lanka.

\section{DECLARATION OF CONFLICT OF INTEREST}

The authors declare no conflict of interest.

\section{REFERENCES}

Akillioglu, H,G., Karakaya, S.(2010). Changes in Total Phenols, Total Flavonoids, and Antioxidant Activities of Common Beans and Pinto Beans after Soaking, Cooking, and Digestion Process. Food Science and
Biotechnology 19(3): 633-639. https://doi.org/10.1007/ s10068-010-0089-8.

Aquino, J.D.S., Batista, K.S., Menezes, F.N.D.D., Lins, P.P., Gomes, J.A.S., Silva, L.A .(2017). Models to Evaluate the Prebiotic Potential of Food. In: M.C. Hueda (Eds.), Functional Food:Improve Health Through Adequate Food, IntechOpen, Croatia Pp.235-256. https://doi. org/10.5772/INTECHOPEN.69174.

Calabrò, S., Tudisco, R., Balestrieri, A., Piccolo, G., Infascelli, F., Cutrignelli, M.I . (2009) Fermentation characteristics of different grain legumes cultivars with the in vitro gas production technique. Italian Journal of Animal Science 8(2): 280-280. https://doi.org/10.4081/ ijas.2009.s2.280.

Campbell, J.M., Fahey, G.C., Wolf, B.W .(1997). Selected Indigestible Oligosaccharides Affect Large Bowel Mass, Cecal and Fecal Short-Chain Fatty Acids , pH and Microflora in Rats. Journal of Nutrition 127(1): 130-136 . https://doi.org/10.1093/jn/127.1.130.

Capuano, E .(2016). The behaviour of dietary fibre in the gastrointestinal tract determines its physiological effect. Critical Reviews in Food Science and Nutrition 57(16): 3543-3564. https://doi.org/10.1080/10408398. 2016.1180501.

Chang, K.C., Chang, D.C., Phatak, L .(1989). Effect of Germination on Oligosaccharides and Nonstarch Polysaccharides in Navy and Pinto Beans. Journal of Food Science 54(6): 1615-1619. https://doi. org/10.1111/j.1365-2621.1989.tb05173.x.

Chen, Y., Chang, S.K., Zhang, Y., Hsu, C.Y., Nannapaneni, R .(2020). Gut microbiota and short chain fatty acid composition as affected by legume type and processing methods as assessed by simulated in vitro digestion assays. Food Chemistry 312, 126040. https://doi. org/10.1016/j.foodchem.2019.126040

Dai, Z., Lyu, W., Xie, M., Yuan, Q., Ye, H., Hu, B., Zhou, L., Zeng, X .(2017). Effects of $\alpha$-Galactooligosaccharides from Chickpeas on High-Fat-Diet-Induced Metabolic Syndrome in Mice. Journal of Agricultural and Food Chemistry 65(15): 3160-3166. https://doi. org/10.1021/acs.jafc. 7 b00489.

Dangsungnoen, P., Moongngarm, A., Deeseenthum, S .(2012). Comparison of Resistant Starch Content and Survival of Lactobacillus spp . on Four Different Sources of Resistant Starch. International Conference on Life Science and Engineering, IACSIT Press, Singapore ,Pp. 39-43. http://doi.org/10.7763/IPCBEE.

Fernando, W.M., Hill, J.E., Zello, G.A., Tyler, R.T., Dahl, W.J., Van Kessel, A.G.(2010). Diets supplemented with chickpea or its main oligosaccharide component raffinose modify faecal microbial composition in healthy adults. Beneficial Microbes 1(2): 197-207. https://doi.org/10.3920/BM2009.0027.

Furuya, S., Sakamoto, K., Takahashi, S. (1979). A new in vitro method for the estimation of digestibility using the intestinal fluid of the pig. British Journal of Nutrition 41(3): 511-520. https://doi.org/10.1079/BJN19790066

Garcha, S., Katyal, P., Sharma, V.(2016). Microbial diversity in soil under different land use systems in sub-mountainous zone of Punjab. Journal of the Indian Society of Soil Science 64(3): 271-275. https://doi. 
org/10.5958/0974-0228.2016.00038.4.

Gibson, G,R., Scott, K.P., Rastall, R.A., Tuohy, K,M., Hotchkiss, A., Dubert-ferrandon, A., Gareau, M., Murphy, E,F., Saulnier, D., Loh, G., Macfarlane, S., Delzenne, N., Ringel, Y., Kozianowski, G., Dickmann, R .(2010). Dietary prebiotics: current status and new definition. Food Science and Technology Bulletin Functional Foods 7(1): 1-19. http://doi. org/10.0.6.80/1476-2137.15880.

Gómez, B., Gullón, B., Yáñez, R., Schols, H., Alonso, J.L.(2016). Prebiotic potential of pectins and pectic oligosaccharides derived from lemon peel wastes and sugar beet pulp : A comparative. Journal of Functional Foods 20: 108-121. https://doi.org/10.1016/j. jff.2015.10.029.

Holscher, H.D .(2017). Dietary Fiber and Prebiotics and the Gastrointestinal Microbiota. Gut Microbes 8(2): 172-184. https://doi.org/10.1080/19490976.2017.1290 756.

Li, W., Feng, J., Xu, Z., Yang, C.(2004). Effects of nonstarch polysaccharides enzymes on pancreatic and small intestinal digestive enzyme activities in piglet fed diets containing high amounts of barley. World Journal of Gastroenterology 10(6): 856-859. http://doi. org/10.3748/wjg.v10.i6.856

Liyanage, R., Kiramage, C., Visvanathan, R., Jayathilake, C., Weththasinghe, P., Bangamuwage R, Jayawaradana ,C.B., Vidanarachchi, J.(2018). Hypolipidemic and hypoglycemic potential of raw, boiled, and sprouted mung beans (Vigna radiata L. Wilczek) in rats. Journal of Food Biochemistry 42(1): e12457. https://doi. org/10.1111/jfbc. 12457 .

Moussou, N., Corzo-Martínez, M., Sanz, M.L., Zaidi, F., Montilla, A., Villamiel, M .(2017) Assessment of Maillard reaction evolution, prebiotic carbohydrates, antioxidant activity and $\alpha$-amylase inhibition in pulse flours. Journal of Food Science and Technology 54(4): 890-900. https://doi.org/10.1007/s13197-016-2298-5.

Mtolo, M., Gerrano, A., Mellem, J.(2017). Effect of simulated gastrointestinal digestion on the phenolic compound content and in vitro antioxidant capacity of processed Cowpea ( V. unguiculata ) cultivars. CyTAJournal of Food 15(3): 391-399.

Muzquiz, M., Varela, A., Burbano, C., Guillamo, E.(2012). Bioactive compounds in legumes: pronutritive and antinutritive actions. Implications for nutrition and health. Phytochemistry Reviews 11(2-3): 227-244. https://doi.org/10.1007/s11101-012-9233-9.

Siva, N., Thavarajah, P., Kumar, S., Thavarajah, D .(2019). Variability in Prebiotic Carbohydrates in Different Market Classes of Chickpea , Common Bean, and Lentil Collected From the American Local Market. Frontiers in Nutrition 6:38. https://dx.doi.org/10.3389/ fnut.2019.00038.

Woyengo, T.A., Jha R., Beltranena, E., Zijlstra, R.T.(2017). In vitro digestion and fermentation characteristics of canola co-products simulate their digestion in the pig intestine. Animal 10(6): 911-918 . https://doi. org/10.1017/S1751731115002566. 